\title{
Association between a vegetarian diet and emotional symptoms: A cross-sectional study among adolescents in four developing countries
}

\section{( 国 Article in press ? )}

- Santivañez-Romani, A. ${ }^{a}$ Email Author,

- Carbajal-Vega, V. ${ }^{\mathrm{b}}$,

- Pereyra-Elías, R. $^{\mathrm{c}}$

- View Correspondence (jump link)

- $\quad$ aSchool of Nutrition and Dietetics, Universidad Peruana de Ciencias Aplicadas, Av. Alameda San Marcos cda. 2, Urb. Los Cedros de Villa, Chorrillos, Lima, 09, Peru

- ${ }^{\mathrm{b}} \mathrm{S}$ chool of Nutrition and Dietetics, Universidad Peruana de Ciencias Aplicadas, Lima, Peru

- $\quad{ }^{\mathrm{c}}$ School of Medicine, Universidad Peruana de Ciencias Aplicadas, Lima, Peru

\section{Abstract View references (34)}

Studies assessing the association between vegetarianism and mental health have found divergent results. Evidence from adolescents in developing countries is scarce. To evaluate the association between a vegetarian diet and emotional symptoms in 15-yearold adolescents from Ethiopia, India, Peru and Vietnam. A cross-sectional, secondary analysis of the Young Lives cohort study was used. The exposure variable was the selfreport of being a vegetarian (yes or no). The outcome was the level of emotional symptoms, numerically evaluated using the score obtained in the subscale "Emotional Symptoms" of the Strengths and Difficulties Questionnaire (SDQ). We calculated crude and adjusted coefficients ( $\beta$ ) with 95\% confidence intervals (95\% CIs), using generalized linear models of the Gaussian family, considering each sentinel site as a cluster. The analysis was stratified by country. Additionally, we made a global analysis including the four countries. A total of 3484 adolescents were analyzed. The overall prevalence of vegetarianism was $4.4 \%$, but it varied between countries (from $0.4 \%$ in Vietnam to $11.5 \%$ in India). The average emotional symptoms score was 3.5 [standard deviation (SD) 2.3] points. The scores were not statistically different between vegetarians and non-vegetarians ( $p>0.05$ ). In the adjusted analysis, in Vietnam, vegetarians had lower emotional symptoms scores on average than non-vegetarians [ $\beta$ : 1.79; $95 \%$ CI: -3.05 to -0.55$]$. No differences were found neither in the other countries nor in the overall sample. There was no association between a vegetarian diet and emotional symptoms in the analyzed adolescents of four developing countries. (C) 2018 Walter de Gruyter GmbH, Berlin/Boston.

\section{Author keywords}

adolescentsaffective symptomsdeveloping countriesvegetarian diet 
- ISSN: 03340139

- CODEN: IJAHE

- Source Type: Journal

- Original language: English

- DOI: $10.1515 /$ ijamh-2018-0130

- Document Type: Article in Press

- Publisher: De Gruyter 